\title{
The Substance Abuse and Crime Prevention Act: Challenges and Promises for Public Health
}

\author{
Behjat Sharif \\ California State University, Los Angeles
}

\begin{abstract}
The Substance Abuse and Crime Prevention Act of 2000 (SACPA), also known as Proposition 36, became effective on July 1, 2001. It allows certain nonviolent drug offenders into community-based drug treatment programs instead of incarceration. Funds have been allocated to the California counties for implementation of the law over a five year period. The program involves the cooperation and collaboration of professionals and agencies within the state's two social service systems: criminal justice and public health. Initial evaluation indicates SACPA's effectiveness in reducing jail and prison populations, saving funds, and providing drug treatment to a large number of SACPA recipients. The implementation process has faced a number of challenges that must be resolved to ensure Californians' trust that treatment is more effective than punishment of drug abusers. The purpose of this paper is to provide an overview of the SACPA initiative and present an analysis of its benefits and challenges. Additionally, suggestions are made for health educators' intervention to ensure effectiveness of SACPA programs in improving public health.
\end{abstract}

(C) 2003 Californian Journal of Health Promotion. All rights reserved.

Keywords: Proposition 26, substance abuse, crime prevention, drug treatment

\section{Introduction}

In California, substance abuse is one of the major problems affecting public health. In 1996, about 60 percent of all adult arrestees in California were found to have used at least one illegal drug shortly before their arrest. In 1997, there were 81,000 alcohol related arrests in Los Angeles County, with 98 percent of them involving misdemeanor charges (Los Angeles County Department of Health Services, 2001). Since 1970 California's prison population has swelled from 10,000 to about 163,000 inmates, an increase due primarily to population growth and the war of drugs (Sauer, 2000). Currently, one of every three of the prisoners incarcerated in the prisons or local jails in California are serving time for a drug-related crime. It is estimated that about 92,000 years of healthy life are lost by Los Angeles county residents directly due to alcohol dependence and drug overdose (Los Angeles County Department of Health Services, 2002).
Substance abuse is widely known to have many health related consequences for both individuals and communities. Abuse of substances contributes to a variety of serious health threats including injuries, depression, suicide and illnesses such as HIV, hepatitis, cirrhosis of liver and other conditions leading to premature death (Jett, 2001). Alcohol and drug abuse are also associated with many serious community public health problems including child and spousal abuse, sexually transmitted diseases, teen pregnancy, and school failure. Most alarming is the disproportionate impact of substance abuse on ethnic minorities. For example, injection drug use associated with HIV/AIDS has accounted for 36 percent of AIDS cases among African American and Hispanic adults compared with 22 percent of all cases among white adults and adolescents (U.S. Department of Health and Human Services, 2002). Alcoholism and drug abuse causes immeasurable pain and suffering for the individuals, families and communities involved. 
Nationwide, substance abuse is also a significant cause of morbidity and mortality. According to the Brown University Center for Alcohol and Addiction Studies, more than half the deaths in the United States are drug and alcohol related. The Healthy People 2010 Report has identified substance abuse as a leading health indicator and reported that among persons age 12 years and older, 36 percent have used an illegal drug. Alcohol and drug abusers are more than 3.5 times likely to be involved in workplace accidents and five times more likely to file for workers' compensation (Brumbaugh, 1998). Substance abuse is also associated with motor vehicle accidents, homicides, and homelessness (U.S. Department of Health and Human Services, 2002). The multiple and detrimental effects of substance abuse annually cost $\$ 143$ billion in preventable health care, criminal justice, social welfare programs and lost productivity.

The issue of substance abuse continues to be a priority in the public health agenda. A variety of prevention programs have been funded to focus on reducing the magnitude of the problem and costs to society. Research findings have confirmed that treatment can help individuals overcome addiction and save related health care costs (Brumbaugh, 1998; Jett, 2001). According to the USDHHS (2002), President Bush's fiscal year 2003 budget includes $\$ 2.3$ billion for substance abuse treatment and prevention programs including the initiatives to close the treatment gap through the Substance Abuse Prevention and Treatment Block Grant and the Program of Regional and National Significance.

In California, a recent solution to the growing problem of substance abuse is SACPA (Proposition 36). This paper provides an overview of this initiative and presents analyses of its benefits and challenges. Additionally, suggestions are made for health educators' contributions to ensure effectiveness of SACPA programs in improving public health.

\section{Background}

In recent years, the California criminal justice system has been overwhelmed with many new laws combating illegal drug use. Passed by 61 percent of California voters on November 7, 2000, SACPA was recently enacted and represents a major breakthrough. The purpose of the initiative is to 1.) divert nonviolent drug offenders, probationers and parolees charged with simple drug possession from incarceration into community-based substance abuse treatment programs, 2.) halt the wasteful expenditures on incarcerations and save jail cells for more serious criminals, and 3.) enhance public safety and improve public health by reducing drug abuse and drug-related crimes (Ford \& Smith, 2001).

The enactment of SACPA allows individuals convicted of their first or second non-violent drug possession offense the opportunity to receive substance abuse treatment instead of incarceration (California Public Defenders Association, 2001). According to the Legislative Analyst's Office (2001), the major provisions of Proposition 36 are changes in sentencing laws and parole violation laws. Since July, 2001, when Proposition 36 became effective, offenders of nonviolent drug possession who are eligible are sentenced to probation and treatment throughout the state of California.

Proposition 36 was promoted by a trio of multimillionaires: Peter Lewis, head of the county's fifth largest auto insurer, Progressive Corporation; George Soros, the international financier; and John Sperling, founder of the forprofit University of Phoenix System (Schwinn, 2001). Proposition 36 is also sponsored by the California Campaign for New Drug Policies.

\section{Funding}

The U.S. Department of Health and Human Services distributes the funds through the California Department of Alcohol and Drug Programs (ADP). Under the act, $\$ 60$ million was appropriated into the Substance Abuse Treatment Trust Fund (Trust Fund) in the year 2000-2001 as a start-up budget. An additional $\$ 120$ million will be appropriated each year for the next five years to the Trust Fund. The average percentage of state budget funds for services to California's fifty-eight counties is 79.1 percent (in a range of 51.5 to 100 percent) and the average budget for criminal justice 
activities is 20.9 percent (in a range of 0 to 48.5 percent). After 2005-2006, the state Governor and the legislature will decide the annual contributions to be allocated for the Trust Fund (Ford \& Smith, 2001).

The legislature has not set a time limit for the expenditure and is open to additional contributions. ADP is responsible for administration and distribution of the funds throughout the state. The funds are distributed to the counties based on a distribution formula which includes, but is not limited to, the followings: base allocation (50 percent), per capita arrests for drug possession violations (25 percent), and substance abuse case loads (25 percent). According to ADP, Los Angeles County was allocated $\$ 30,330,454$ for the 200102 fiscal year. Los Angles is the most populated county with the highest number of arrests and caseloads. The county with the smallest number of cases, Alpine county, received $\$ 149,400$ for the 2001-02 year.

In order for the counties to receive state funds, each must submit an annual implementation plan to ADP (Ford \& Smith, 2001). The plan is not restricted by SACPA and each county can develop a specific strategy according to its needs and professional criteria. Each county plan must identify: a lead agency, the planning process, the types of services and levels of care provided and the client population (probation and parole).

According to SACPA, the counties can use the funds to provide offenders with treatment services, probation supervision, court monitoring, family counseling, vocational training, literacy training, and to pay other miscellaneous fees made necessary by the provision. Proposition 36 requires offenders who are reasonably able to pay for their own drug treatment. The funds cannot be used to provide for drug testing costs. SACPA precluded funding for drug testing in order to promote the expenditure of funds for the state's most critical need: the expansion and improvement of drug treatment services. ADP reserves the right to earmark a portion of the funds to establish contracts directly with private drug treatment service providers in counties that have failed to meet adequate drug treatment services with their existing programs (Drug Policy Alliance, 2002).

Since the money from the fund does not pay for every single service, the state and counties must identify supplementary funding sources. Medical care, for example, can cover some drug services and related mental health treatments. Since Proposition 36 requires some offenders to participate in vocational and literacy training programs as a condition of their probation, community colleges and adult education training programs operated by local school districts can be considered. Moreover, the funds from the Work Investment Act may be used to pay for some of those who need vocational training. Private health insurance can provide substantial reimbursement if an individual pays for his or her own treatment. For facilities that require expansion of residential or outpatient treatment programs, the state can provide low interest loans (as low as three percent) through the existing loan program operated by the California Health Facilities Financing Authority (Legislative Analysts Office, 2001).

Proposition 36's scope and reach has been extended by Senate Bill 223 in a number of ways including provision for drug testing. SB 223 allocated $\$ 8$ million of federal block grant funds to be used by the counties for drug testing of the SACPA clients. The additional funds are helpful since $91.6 \%$ (11) of the twelve largest counties will require drug testing of SACPA (Ford \& Smith, 2001). According to the SACPA Progress Report (Uelmen, Abrahamson, Appel, Cox \& Tylor, 2002), SB 223 clarifies that the results of drug tests shall be used as a treatment tool rather than to punish the client. SB 223 amends SACPA to clarify the ability of the courts to expel clients from drug treatment and incarcerate them on the grounds that they are "unamenable to treatment." Also, SB 223 allows individuals to enter a program operated by the direction of Veterans Health Administration for their term treatment program or drug treatment.

\section{Sentencing}

The passage of Proposition 36 has changed the way criminal justice sentences the substance abuser in California. SACPA is provided to 
eligible offenders throughout the state. After a convicted offender agrees to participate in a drug treatment program, the probation department will proceed to notify a drug treatment provider. It is the responsibility of the provider to develop a treatment plan that is specifically designed for the individual. The plan is then presented to the probation department within thirty days of the original notification. Once the plan is approved, the court, as a condition of the probation, requires the offender to participate in and complete the drug treatment program. Additionally, the court may also require offenders to participate in vocational training, family counseling, literacy training and community service. There is no limitation in setting conditions for probation and as a result the court is free to require drug testing or psychological counseling for the offender. The treatment provider is required to submit progress reports about the offender on a quarterly basis. (Dabney, Gurwitz, Pipes, Rubin, Storton, 2000).

After completion of the probation and treatment, the offender is released from court supervision and probation conditions. The defendant can petition the court for dismissal of charges and if the court finds the defendant's performance successful, the conviction may be dismissed. The dismissed conviction must still be disclosed by the offender when applying for certain jobs and licenses and in situations such as becoming a juror (Dabney et al., 2000).

Offenders are not eligible for SACPA if they have a prior conviction for a serious violent felony unless they have been out of prison and crime free for at least five years (Alcoholism \& Drug Abuse Weekly, 2002). SACPA also allows those on probation or parole for specific crimes to participate in community-based drug treatment programs to avoid re-incarceration for drug-related violations of their probation or parole. To ensure that convicted drug offenders participating in SACPA programs are not a threat to the safety of society, the following drug offenders are ineligible for proposition 36 programs: certain individuals with prior California three strike law, individuals convicted of non-drug related cases in the same proceeding, individuals in possession of firearms, those who refuse probation, and certain individuals who previously received two proposition 36 probations (California Public Defenders Association, 2001).

\section{Treatment}

SACPA provides a variety of treatment options for those that qualify. The programs include, but are not limited to: outpatient treatment, half-way house treatment, narcotic replacement therapy (methadone), drug education and prevention courses and limited inpatient or residential treatment as needed to address special detoxification, relapse, or severe dependence (Dabney et al., 2000). A large number of the participants in SACPA will be young individuals who have the potential to live a productive life but need education, career training, and other support (Wittman, 2001).

The length of any treatment is limited to a maximum of twelve months with six additional months for aftercare. In addition to mandatory completion of a certified drug treatment program, SACPA allows the court to hold the defendant accountable for the cost of drug treatment and or applicable fines if it is proved that the individual can afford such payments. The funds are provided for drug testing only for those drug offenders who would be unable to pay for treatment without financial assistance through SACPA. Approximately eighty-seven percent of the counties will require drug testing of SACPA clients using non-SACPA funding sources. About ninety-one percent of the counties selected behavioral professionals or alcohol and other drug professionals to provide assessment and placement services to SACPA eligible clients (Ford \& Smith, 2001).

In the six counties examined at the beginning of March 2002, a total of 13,695 SACPA clients had been referred to treatment. Table 1 and Figure 1 show a total of $9,334(68 \%)$ of the referrals being active in treatment, a higher than average rates according to treatment experts (Prop 36 Update, 2002). Reason given for those not active included waiting to be assessed and placed in treatment, being in between programs, or non-compliance. According to the SACPA Progress Report, by January 25, 2002 there were 
about 3, 596 parolees referred to SACPA. The California Department of Corrections reported that only thirty-one warrants were issued for those who failed to meet the probation conditions set by the court (Uelmen et al., 2002).
This showed that SACPA has already made a difference in diverting offenders to rehabilitation and treatment rather than sentencing them to prison without getting a chance to overcome their addiction.

Table 1

Number of Referrals Active in Treatment in Six Counties

\begin{tabular}{|l|r|r|r|}
\hline \multicolumn{1}{|c|}{ County } & $\begin{array}{c}\text { Total Number of } \\
\text { Referrals }\end{array}$ & $\begin{array}{c}\text { Total Number of Clients } \\
\text { Active in Treatment }\end{array}$ & $\begin{array}{c}\text { Percentage of Referrals } \\
\text { Active in treatment }\end{array}$ \\
\hline Contra Costa & 565 & 346 & $61 \%$ \\
\hline Los Angeles & 6,602 & 5,120 & $78 \%$ \\
\hline Sacramento & 1,123 & 600 & $53 \%$ \\
\hline San Bernardino & 1,773 & 942 & $53 \%$ \\
\hline San Diego & 1,964 & 1,422 & $72 \%$ \\
\hline Ventura & 1,668 & 903 & $54 \%$ \\
\hline
\end{tabular}

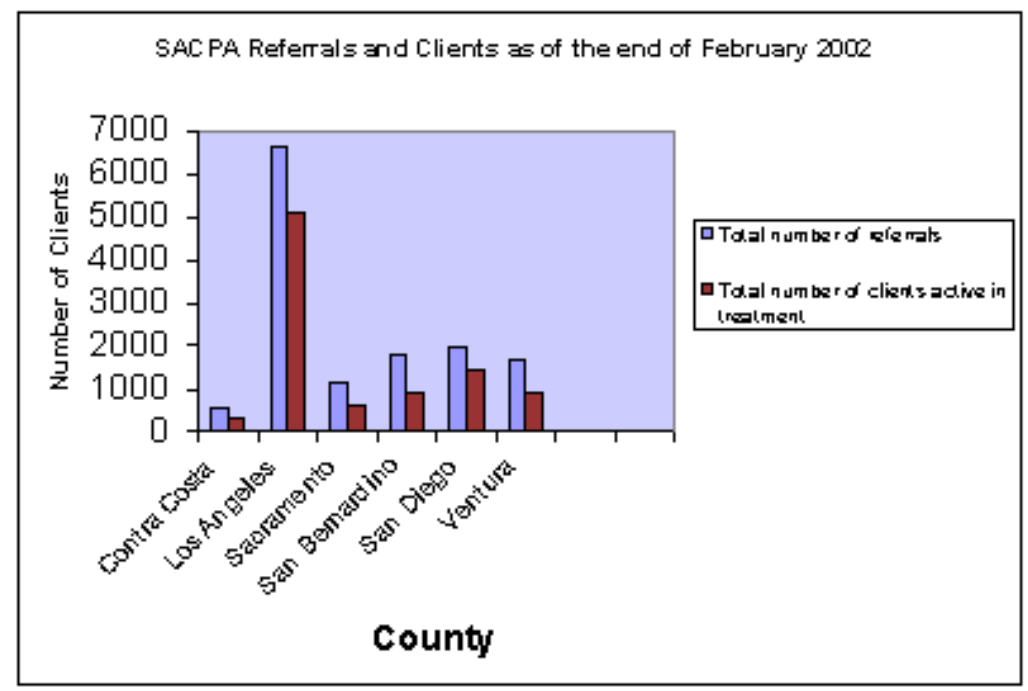

Figure 1

Number of Referrals Active in Treatment in Six Counties

\section{Implementation}

The Legislative Analyst's Office (2000) reported that there are several agencies involved in the implementation of proposition 36. At the state level, the Department of Alcohol and Drug Program, The Board of Prison Terms and the California Department of Corrections are the key players. Each agency has specific function. The DADP is in charge of distributing the funds to the counties, licensing or certifying the drug treatment programs and collecting data from counties; it also audits county expenditures and evaluates the measure's effectiveness. The Board of Prison Terms sets the revocation 
criteria for parole violators who are directed into treatment and also decides when to modify or intensify the treatment program and revoke parole. The California Department of Corrections is in charge of supervising and monitoring parole violators who have been directed into treatment by the Board of Prison Terms. It also reports violators of revocation criteria to the BPT and provides treatment services to probationers and parolees directed into treatment within the county.

At the local level, the trial courts also revoke probation for those who violate the law. The county probation department supervises and monitors probationers directed into treatment, and reports violations of drug treatment revocation criteria to courts. Lastly, the educational, social and health services agencies provide services prescribed by the courts such as vocational and literacy training and family counseling.

The counties are implementing SACPA in a variety of ways. According to SACPA Progress Report, about 90 percent of the state's fifty-eight counties chose their local health department to serve as the lead agency responsible for implementation of SACPA in the 2000-2001 fiscal year. The report also credits collaboration between criminal justice and public health agencies for the success of SACPA during its first six months of existence. Counties also developed programs and services based on the sharing of information among leading agencies and data collected by the State SACPA Task Force. The Task Force was developed in January 2001 by DADP to collect data related to SACPA and is comprised of key stakeholders including court members, probation and parole officers, drug treatment providers, prosecutors, public defenders, the Attorney General and the initiative's opponents. The Task Force holds their requisite meeting monthly and in a recent report indicated that even though SACPA is in its infancy and more information is needed to fully assess its impact, the initial feedback has been "extremely positive" (Uelmen et al., 2002).

Technology is playing a key role in the implementation of SACPA. San Mateo county was the first to implement the use of a magnetic card to monitor drug offenders, who must carry the card with them at all times. This "smart card" is embedded with the defendant's pertinent treatment information. The Alcohol and Drug Abuse Weekly (2002) reported that the card allows criminal justice and treatment staff to check on the offender's status and ensure that the conditions of participation in the diversion program are being met while also meeting federal requirements of confidentiality protection.

Proposition 36 has only been implemented for nearly one year but the results so far have been promising. During SACPA's initial weeks, some counties enrolled several hundred offenders. Santa Clara County alone enrolled over 500 (Alcohol and Drug Abuse Weekly, 2002). To date, the majority of the California counties have diverted fewer offenders than originally anticipated. However, as in the beginning of any new program, the counties are waiting to see if the diversion program will truly profit California communities and assist those suffering from addiction.

\section{Evaluation}

The SACPA provides up to $\$ 3.3$ million for a mandated annual study to evaluate the effectiveness and impact of the funded treatment programs. The requisite evaluation includes, but is not limited to assessments of: the implementation process, the decrease in incarceration costs, the reduction of crimes, the construction of new prisons and jails, welfare costs and other related expenses. Each year, up to 0.5 percent of these funds shall be allocated for a long term study conducted by a California public university. The University of California at Los Angeles has been chosen to conduct the required evaluation (Dabney et al., 2000). According to Integrated Substance Abuse Programs (2002) at UCLA, the evaluation will assess the cost offset resulting from SACPA and its impact on public health and safety. The evaluation will also assess how the criminal justice and treatment programs respond to and learn from the implementation of Proposition 36. 


\section{Preliminary Benefits}

The notion of providing drug offenders with treatment rather than sending them to jail has obvious appeal from both public health and criminal justice perspectives. Through SACPA, drug abusers are getting treatment to help break the cycle of addiction and crime. They are also receiving medical care, family counseling, vocational training and other life enhancing skills. Instead of being punished for their illness, they are given the tools and services for rehabilitation and treatment.

Proposition 36 is also freeing up prison cells to be used for more violent criminals. In 1988, California held 5,140 people in prison whose greatest charge was simple drug possession. By the end of 1999, the figure had risen to 19,753 , a dramatic increase cited often by supporters during the Proposition 36 campaign. SACPA has been incontrovertibly effective in quickly reducing the state's prison population. According to data from California Department of Correction, nearly 4,000 fewer people were serving time in state prisons for drug possession one year after the passage of Proposition 36. The number of prisoners whose greatest offense was drug possessions, between December 2000 to 2001 , fell from 19,736 to 15,781 a difference of 3,955 . In this period the overall California prison population declined from 160,124 to 157,096 , a total of 3,028 . Without Proposition 36 , the state prison population would have increased by about 1,000 in the same period (California Campaign for New Drug Policies, 2002). While the number of violent criminals behind the bars increased in the past year, Proposition 36 has quickly reduced the overall state prison population 20 percent (California Campaign for New Drug Policies 2002). The California Department of Corrections predicted that Proposition 36 alone accounts for a projected cut in the prisons' population of about 5,440 inmates next year and by more than 7, 700 inmates by 2007 . Therefore, a senate budget subcommittee voted to stop all spending on a new maximum security prison near Delano, California (Drug Policy Alliance, 2002). As the number of prisoners decreases, the need for a new prison will evaporate entirely, saving the state between $\$ 474$ to $\$ 575$ million (California Campaign for New Drug Policies, 2000).

Proposition 36 has been seen as an important tool that will help the state to save millions of dollars in incarceration cost, decrease overcrowding in prisons and improve the working conditions of officers. Studies have shown that the cost of incarceration of drug offenders is about seven times more than treatment (Khoo, 2000; Sauer, 2000). The California Campaign for New Drug Policies (2000) and Drug Policy Alliance, (2002) indicated that SACPA can save about $\$ 20,000$ per year per individual referred to treatment instead of incarceration. It is reported that the average cost to the taxpayers in California per inmate is $\$ 23,406$ per year whereas the average cost of a full drug treatment program per client is $\$ 4,300$. Additionally, the state's Legislative Analysis Office, (2000) projected that in the next five year period approximately 37,000 offenders will be diverted from the California correctional system into community-based treatment programs. Proposition 36 is predicted to save taxpayers an estimated 1.5 billion in this period.

According to Drug Policy Alliance (2002), a total of 13, 695 individuals have been referred to treatment under Proposition 36 in Contra Costa, Los Angeles, Sacramento, San Bernardino, San Diego and Ventura counties. In San Mateo county, the courts have sent an average of one person a day into treatment for addiction instead of incarceration (Whitney \& Hitty, 2002). As a result of the diversion, the California Department of Corrections has reported that the state's population of women inmates has dropped 10 percent. Women who have been referred to treatment centers learn basic skills such as budgeting, parenting, cooking and cleaning. A study was conducted six months after the enactment of Proposition 36 to evaluate the programs in seven counties, and of the total number referred to a drug treatment, 71 percent were actively in treatment with a range of 55 percent to 86 percent (Uelmen et al., 2002). A number of reasons were given for those not participating in the program including failure to appear in court, a lack of motivation by the 
client, communication problems and a lack of transportation. Additionally, in this period over 3,500 parolees were referred to treatment because of violation of their parole. Of these parolees, only thirty one individuals did not follow through with their treatment requirements.

Moreover, SACPA can help reduce some of the risks involving public health and law enforcement. Through family counseling, literacy training, drug education and prevention and treatment programs, SAPCA will help strengthen individuals, families and communities. Recovered drug offenders can be enabled to become productive family members and serve as role models in their communities.

\section{Current Issues: Health Educators' Role}

So far, Proposition 36 has experienced several obstacles, most problematically, a low budget. A number of counties have indicated that SACPA funding will be insufficient to provide the treatment and supervision services necessary under the act (Legislative Analyst's Office, 2001). Several counties including Santa Clara, Los Angeles and San Diego reported at a recent California legislative hearing that those eligible for treatment under Proposition 36 are more severe addicts than expected and suffer from other problems such as mental illness, homelessness, and unemployment that complicate treatment and add costs for aftercare services (Correction Forum, 2002). In addition, many drug users who have been diverted to drug treatment are not showing up. Some opt for a jail or probation sentence and some face jail if they fail to pay the $\$ 360$ per month charge for their treatment (Duncan, 2001).

Inadequate space is another concern. Many treatment centers are already filled to capacity and have a long waiting list. Some estimates indicate that treatment centers will be asked to find space for about 40,000 people a year (Schwinn, 2001). There is reluctance among nonprofit groups to take on the expense of expanding treatment programs when there is uncertainty about the number of future referrals. Additionally, California residents claim substance abuse as a priority but continue to oppose the building of new treatment centers in their neighborhoods. Schwinn (2001) stated that a pressing need for space requires creative solutions, but some experienced service providers voice concerns about rapid expansion. They warn of profiteers hungry for government funding as well as well-intentioned but inadequately trained practitioners and substandard facilities.

Among other concerns are potential biases among members of the criminal justice system that may influence their treatment of offenders. According to Uelmen et al. (2002), SCAPA clients are not being placed in methadone maintenance programs according to the level of demand. This has been due to bias against narcotic treatment coupled with lack of provider contracts with the counties to provide methadone services. Also, sober living facilities must be an integral part of SACPA programs. While not treatment facilities, sober living facilities allow an individual to live among a group of peers in a safe, quality- controlled environment. There is a need to establish licensure for these facilities and develop statewide monitoring of their quality (Wittman, 2001).

There are other challenges that California counties have faced related to the implementation of SACPA. Often it is not clear what is meant by an offender failing to complete treatment (Khoo, 2000). Some counties have had to develop new assessments tools or modify the existing ones to identify the treatment needs of the eligible population. The counties have also had to provide a variety of treatment services to meet the diverse needs of the SACPA referred population, develop strategies to expand drug treatment capacity and consider how the new treatment services will affect existing treatment programs. They must determine the type and levels of supervision required and monitor the services needed by SACPA clients. Additionally, there is a need to develop quality control mechanisms to ensure that the SACPA funded programs are delivering high quality services to clients. 
More importantly, there has been no serious attention given to closing the gap among California's diverse population, even though the ravages of drug abuse hit ethnic minorities hardest. Although patterns of drug use are relatively consistent across racial groups, ethnic minorities are more likely to be convicted on drug-related charges and have considerably less access to treatment facilities. According to 1996 federal government statistics, 5.2 percent of Hispanic, 6.1 percent of whites, and 7.5 percent of blacks reported using drugs within the past month. In the same year, 23 percent of those sentenced to state prison for drug offenses were Hispanic, 20 percent white and 57 percent were black. Additionally, individuals admitted into treatment in 1996 were 10.8 percent Hispanic, 73.3 percent white and 24.9 percent black (California Campaign for New Drug Policies, 2000). SACPA is expected to be an equal opportunity initiative providing treatment services to eligible clients regardless of race or economic status. Reports on SACPA's first year of implementation indicate that issues of equity and attention to ethnic minorities have not been given serious consideration.

It is too early to draw hard conclusions about challenges facing SACPA. However, its further success will require addressing the initial shortcomings and projected future concerns. The situation offers tremendous opportunities for positive intervention that can contribute to the success of SACPA. Areas in which health educators can have significant roles include:

- Education and training. Increasing efforts to educate members of the criminal justice system especially judges and probation officers. These individuals must know more about drug abuse, addiction and effective treatment programs. Personal ideologies or impressions against certain treatments should not influence the assessment of offenders, their treatment plans or the purging of their records.

- Collaboration. Promoting effective
communication and close working relationships among all key players at the state and local levels. The measure requires collaboration between two social systems, public health and criminal justice. The courts must adhere to the treatment plan and assessments by the substance abuse treatment professionals.

- Increased participation. Enhancing lead agencies' capacity in communication and coordination of paperwork between courts, probation departments and treatment facilities to prevent client confusion. It is essential to develop clear, concise and culturally appropriate materials in the client's primary language.

- Treatment needs. Conducting an inventory of the counties' drug treatment services to identify the needs, determine the gaps and develop strategies to address all requirements of SACPA clients including co-existing mental health disorders, homelessness and social predicaments.

- Closing the gap. Addressing the serious absence of programs that provide a range of treatment modalities related to cultural, ethnic and gender specific needs of the SACPA clients. Although early efforts among the treatment programs have been to accommodate the influx of clients, providers must be seriously conscious of the state's diversity and the nation's goal in eliminating health disparities in ethnic populations.

- Supervision and monitoring. Identifying factors to improve the process of supervising and monitoring probationers while in treatment. While appropriate technology and the use of smart cards can facilitate the process, there is a need to ensure a client's commitment to change as opposed to his or her fear of punishment.

- Distribution of funds. Enhancing the contract with counties to ease reporting and auditing requirements. The SACPA funding formula must consider incentives to counties to improve their programs, develop new programs and provide educational training for their staff. 
- Program effectiveness. Promoting provision of scientifically sound programs, carefully selected reviewers of program proposals, and state-of- the-art program planning and implementation. Assisting treatment providers in carefully evaluating their programs and providing data-based claims when reporting their successes and challenges in serving SACPA clients.

\section{Conclusion}

Although there is no single solution or quick resolution to the problem of substance abuse, early reports and data indicate that SACPA appears to make positive progress towards its promises to the state. The multidisciplinary nature of Proposition 36 and the adjusting of emphasis away from law enforcement and toward public health has been a welcome paradigm shift. SACPA has been effective in a dramatic reduction of the prison population and may improve levels of crime and violence. Thousands of people are being diverted from jails and prisons to community-based drug treatment programs and relate services. While still in infancy SACPA has obvious limitations that must be addressed to insure its programs' effectiveness in the long term. However, SACPA has the potential to provide urgently needed drug treatment programs and related services to tens of thousands of Californians, save taxpayers many millions of dollars and most importantly, make a significant contribution to improvement of the state's public health.

\section{References}

Alcoholism \& Drug Abuse Weekly. (2002, February 25). California county uses "smart card" as Proposition 36 trouble shooter. Farmington Hills, MI: Gale Group, Inc.

Brumbaugh, A. (1998). The cost of untreated chemical dependency. Retrieved February 7, 2003, from http://www.silcom.com/ alexb/cost.htm

California Campaign for New Drug Policies. (2002, May 1). State prison population of drug abusers dropped 20\% in 1 year after Prop.36. Retrieved February 7, 2003, from http://www.drugreform.org/news.tpl?action=2\&newsid=102022115660424

California Campaign for New Drug Policies. (2003). Nationwide drug reform votes. Retrieved February 7, 2003, from http://www.drugreform.org/prop36/basicfacts.tpl

California Campaign for New Drug Policies. (2000). The California correctional system and the Substance Abuse and Crime Prevention Act: A California voter initiative. Retrieved February 7, 2003, from http://www.drugreform.org

California Department of Alcohol and Drug Programs. (2000). Substance Abuse and Crime Prevention Act of 2000 preliminary allocation fiscal year 2001-02. Retrieved February 7, 2003, from http://www.governmentguide.com/govsite.adp?bread=*Main*url=http\%3A//www.my.ca.gov

California Public Defenders Association. (April, 2001). An analysis of Proposition 36: Substance Abuse and Crime Prevention Act of 2000.

Corrections Forum Staff. (March/April 2002). Proposition 36 attracting more "hard core" addicts than expected. Corrections Forum, 11(2), 91.

Dabney, J., Gurwitz, B., Pipes, L. D., Rubin, J., Storton, K. (2000). Implementing Proposition 36: Substance Abuse and Crime Prevention Act of 2000. California District Attorneys Association.

Drug Policy Alliance. (2002). California proposition 36: The Substance Abuse and Crime Prevention Act of 2000. Retrieved February 7, 2003, from http://www.prop36.org

Drug Policy Alliance. (2002, May 1). Early reports indicate that Prop36 is working as intended. Retrieved February 7, 2003, from http://Prop36.org/pr050102.html

Duncan, S. D. (2001, August 6). There is downside to Prop. 36 program. Media Awareness Project. Retrieved February 7, 2003, from http://www.mapinc.org/drugnews/v01/n1443/a04.html?1487 
Ford, W. E., \& Smith, M. J. (2001). Substance Abuse and Crime Prevention Act of 2000: Analysis of plans from the 58 counties. Washington D.C.: Health System Research, Inc.

Harrison, B. (2001). Rethinking drug policy. State Legislature, 27(7).

Integrated Substance Abuse Programs. (2002). Prop 36: The Substance Abuse and Crime Prevention Act. Retrieved from http://www.medsch.ucla.edu/som/npi/DARC?sa/prop36/pro36.htm

Jett, K. P. (2001). Proposition 36: Issues and challenges. Journal of Psychoactive Drugs, 33. 321-328.

Khoo, A ( 2000). Prop 36: Treatment, not prison, for drug possession. The Substance Abuse and Crime Prevention Act. Retrieved February 7, 2003, from http://www.4children.org/news/900pr36.htm

Legislative Analyst's Office. (2000). Implementing Proposition 36: Issues, challenges, and opportunities Retrieved February 7, 2003, from http://www.lao.ca.gov/2000_reports/prop36/121400_prop_36.html

Legislative Analysts' Office. (2001). Analysis of the 2001-02 budget bill: Implementation of Proposition 36. Retrieved February 7, 2003, from http://www.lao.ca.gov/analysis_2001/health_ss/hss 3 CC Prop36.htm

Los Angeles County Department of Health Services. (2001). The health of Angelenos: 2000; A comprehensive report on the health of the residents of Los Angeles County. Los Angeles, CA: Los Angeles County Department of Health Services, Office of Health Assessment and Epidemiology.

Los Angeles County Department of Health Services. (2002). Recent health trends in Los Angeles County. Prop 36 Update. (April 9, 2002). Retrieved February 7, 2003, from http://www.prop36.org/updates.html

Sauer, M. (2000, October 17). Jail time or treatment? Which one is better? The San Diego UnionTribune.

Schwinn, E. (2001). Preparing for the rush. Chronicle of Philanthropy, 13(14), 41-43.

Uelmen, G., Abrahamson, D. N., Appel, J. K., Cox, A. L. \& Tylor, W. A. (2002). Substance Abuse and Crime Prevention Act of 2000: Progress report. Drug Policy Alliance.

U. S. Department of Health and Human Services. (2002). Substance abuse- a national challenge: Prevention, treatment and research. HHS Fact Sheet. Retrieved February 7, 2003, from http://www.hhs.gov/news/press/2002pres/subabuse.html

U.S. Department of Health and Human Services. (2000). Healthy People 2010: Leading health indicators Retrieved February 7, 2003, from http://www.health.gov/healthypeople/Document/html/uih/uih 4.htm

Whitney, J. \& Hitty, S. (2002, February23). US A; Prop36 moving addicts to recovery. San Mateo County Times. Retrieved February 7, 2003, from http://mapinc.org/drugnews/v02/n322/a03.html?144

Wittman, F. D. (2001). Prevention, community service and Proposition 36. Journal of Psychoactive Drugs, 33, 343-351.

Author Information

Bejhat Sharif, PhD

California State University, Los Angeles 